\title{
Entrevista
}

\section{ENTREVISTA COM INÁ CAMARGO COSTA - DE DERROTA EM DERROTA, A LUTA CONTINUA}

Entrevista realizada em 10 de julho de 2018, por Matheus Cosmo e Roberta Carbone. 
REVISTA ASPAS - Nós estamos dedicando esse número da revista a pensar 1968-2018 e queríamos te ouvir falar sobre isso.

INÁ CAMARGO COSTA - Então vamos já entrar no assunto. Eu sugiro uma lição de casa para vocês e não só para fins de edição, como também para se ligar nas coisas: vocês conhecem o site Opera Mundi? O Breno Altman faz ali uma análise de vinte minutos sobre 1968 na França que é a coisa mais primorosa que já vi. É uma análise política, repetindo, a mais penetrante que eu já li ou ouvi na minha vida. Outra referência é um filme que tem no YouTube e que é de gritar - para esta veterana, claro. O nome do cineasta é William Klein. Ele era da turma que promoveu o Maio de 68 na França e deu uma de Dziga Vertov: câmera na mão e presença nos lugares onde as coisas aconteciam. Depois ele editou esse material, que é uma cobertura do começo até a derrota de 1968 na França. Pela primeira vez eu vi imagens da famosa assembleia popular em um estádio com milhares de pessoas. E não era um mero ato público, era uma assembleia popular para deliberar sobre os próximos passos. $O$ filme se chama Longas noites e manhãs breves e tem legenda em português de Portugal.

ASPAS - Nós também estamos tentando pensar no que foi e no que não foi esse processo para o teatro. E, voltando ao prefácio que o Roberto Schwarz escreveu para o seu livro $A$ hora do teatro épico, ele fala que: “Com o golpe de 1964, a trajetória ficou interrompida. O teatro, em parte reagiu, em parte se ajustou, e em parte se ajustou reagindo". Nós queríamos entender o que foi esse processo.

INÁ - Esse é mais ou menos o resultado da minha tese. Mas, para entender esse diálogo, é preciso entender que a minha tese tem como solo, terra firme, o ensaio do Roberto Schwarz "Cultura e política - 1964-1968". É lógico que, em alguns pontos, eu às vezes divergia dele. $E$ uma das divergências foi que ele tirou o Centro Popular de Cultura [CPC] da roda, eu coloquei e ele concorda. Mas para entender este ponto, é preciso saber que ele foi para o exílio e não teve acesso a esses materiais. Ele já era professor na época e não teve contato com os desdobramentos do CPC. Ele conhecia o CPC por ouvir dizer e, como era muito exigente por causa da formação literária, achava que era brincadeira de criança, coisa de estudante, que era ótimo que fosse feito, mas não iria 
dedicar seu tempo ao assunto. Eu é que dediquei. Este é um dos pontos de divergência. Melhor que divergência, seria dizer desdobramento das teses dele mesmo. Vamos então começar pelo "reagiu ajustando", que diz respeito ao Teatro Oficina e ao Tropicalismo. Ajustar naquele contexto quer dizer aderir ao mercado e, uma vez adepto, se comportar como quem está fazendo revolução. A tradução disso é a última frase que eu escrevi no doutorado: "Transformou a luta em mercadoria". Eu puxei esse fio do Walter Benjamin, que fala a mesma coisa sobre os artistas alemães e franceses. Se já é grave - segundo Benjamin - meramente registrar a luta do ponto de vista literário, porque é transformar os registros em mercadoria, muito mais grave é, na condição de mercadoria, encenar (no sentido de fingir) a luta. Isso é o Oficina e isso é o Tropicalismo. O Roberto Schwarz nunca disse com todas as palavras, mas é isto que ele está falando. O mais visível e o que mais tem registro é justamente este setor. E é no pós-1968 que isso fica evidente, mas, no caso do Oficina, já é em 1967. O rei da vela já era isso. Tudo deita raiz e, no caso do Brasil, tudo deita raiz no processo que vai de meados dos anos 1950 até o golpe de 1964. Passemos ao "em parte reagiu", que são os nossos companheiros, principalmente os vinculados ao Partidão, o PCB, ou dele simpatizantes, seja da bandeira de luta, do programa e, consequentemente, dos critérios estéticos que produziram muita coisa relevante ao longo dos anos 1960. Mas que de 1967, 1968 em diante, naturalmente, submergiram e em 1968, eu diria, jogaram a toalha. Naquele texto do Vianinha, "Um pouco de pessedismo não faz mal a ninguém", já está no título, isto é: vamos retomar - e isso está dito com todas as palavras - o programa político do pré-1964, a aliança de classes na política e nas artes. Só que isso já era mesmo uma bandeira fadada ao ocaso. Não teve consequências e, em larga medida - neste sentido nós podemos tomar o Dias Gomes como exemplo -, se traduziu em uma adesão menos "radical" do que a adesão tropicalista, que é a passagem de quase todos os veteranos do CPC mais o Dias Gomes, que não chegou lá, para a TV Globo. Pensar na Rede Globo como o desaguadouro da produção cultural, toda ela, é importante para vocês, porque é entender que, com a Globo pautando o mercado de consumo cultural, acabou a conversa. Se tivesse que surgir uma alternativa, como já surgiu, seria completamente fora do esquema da indústria cultural. Variam também os graus de crítica, mas tem que ser fora. Aí a pauta volta para 1968 e passa a 
ser a reflexão sobre os meios de comunicação e a industrialização da cultura, tal como definidos por Guy Debord que, em 1967, publicou o livro A sociedade do espetáculo. Aliás, é outra dica para vocês o filme $A$ sociedade do espetáculo, do Guy Debord, que incorpora cenas do Maio de 1968 francês. Este filme avalia, inclusive, a própria derrota de Maio de 1968, mas reafirma a pauta. Mas o Guy Debord é o oposto do processo brasileiro, porque ele reitera que a luta é de classes e, se não for de classe contra classe, cultura revolucionária contra cultura industrializada, não tem horizonte para a humanidade. Ele não diz isso com os termos que eu estou usando, mas é isso o que ele está dizendo no livro e no filme.

ASPAS - Quando se acompanha o processo desde 1958, a partir da estreia de Eles não usam black-tie no Teatro de Arena, o teatro ainda parece conseguir se sustentar nesse momento, por meio de prêmios, da bilheteria. Mas, dez anos depois, em 1968, o teatro desaparece junto com o seu público. Como se dá esse processo de desmonte, essa perda de público e de verba?

INÁ - Você tem que começar pelo básico. O processo começa com a perseguição homem a homem por parte da ditadura. A ditadura prendeu, torturou e exilou o Boal! Todos que estavam em cena no ano de 1964 passaram pelo menos dois, três meses sumidos, porque a ditadura estava nos calcanhares deles! Houve, inclusive, um combate físico. A produção foi eliminada. Uma estrutura como a do Arena, do jeito que a censura veio para cima, não tinha como se sustentar. Uma coisa é morrer o Teatro Brasileiro de Comédia [TBC] por falta de dinheiro e público, porque - agora citando o Luiz Carlos Moreira -, o TBC foi a última tentativa de produzir teatro para o mercado no Brasil. O fracasso do TBC deixou claro que não existe mercado convencional para o teatro. Tem mercado no Brasil para ópera, balé, orquestras, porque é o Brasil inserido no circuito internacional de circulação de produtos: vem, apresenta e vai embora. Mas para a produção local não tem mercado. A experiência do TBC mostrou isso. O TBC foi estatizado e, uma vez estatizado, conseguiu uma sobrevida de aproximadamente dez anos, mas nem estatizado ele conseguiu se sustentar. A questão da produção já é ponto pacífico: se o horizonte é algum tipo de mercado, vá fazer outra coisa no teatro, porque não existe 
mercado para teatro no Brasil. No livro $A$ luta dos grupos teatrais de São Paulo por políticas públicas, o argumento do Moreira em defesa das leis no plural - de fomento é justamente esse. O problema é que com a ditadura não se tratava de mero fim de jogo. Foi combate, inclusive físico. E acho que a manifestação extrema disso é o exílio do Boal. A ditadura não estava para brincadeira. E, no caso de São Paulo, a nossa burguesia também não estava para brincadeira. A palavra de ordem dos vitoriosos passou a ser: "Chega de graça e desse negócio de teatro político! Nós queremos sinestesias, queremos experiências sensoriais, queremos estímulo para a imaginação..., era isso que a burguesia queria e, portanto, não o teatro político tal como ele se desenhou a partir de 1958. Este processo não é natural, é um processo de luta de classes que foi vencido pela classe dominante. E, uma vez que venceu, ela abriu espaço para os valores dela. Em todo o caso, o processo de resistência se manteve até quase o fim da década de 1970, é bom não esquecer. Para não ir muito longe, é só você acompanhar a reorganização dos veteranos do Arena liderada pelo Maurício Segall, que levou todo mundo para o teatro São Pedro, o que depois se ramificou para o Taib, Teatro de Arte Israelita Brasileiro, na rua Três Rios. Isso era teatro de resistência. A resistência prosseguiu com o mesmo tipo de público que o Arena tinha. E eu sei que em outros lugares do Brasil aconteceu a mesma coisa.

\section{ASPAS - Isso também se aplica ao Grupo Opinião no Rio de Janeiro?}

INÁ - Eu acho que, em parte, o caso do Opinião é similar à resistência aqui. Graças ao Opinião, até hoje no Rio de Janeiro existe uma companhia como a Ensaio Aberto. Mas é bom não esquecer que o Rio de Janeiro é uma praça controlada pela Globo e seus tentáculos. Tem aquelas escolas de teatro que já formam atores para Globo, e ela mais ou menos controla o cenário geral. Até quando o Opinião durou?

\section{ASPAS - O João das Neves mantém o Opinião até o início da década} de 1980.

INÁ - Então, é mais ou menos paralelo ao que o Maurício segurou aqui em São Paulo. Mas, não se esqueça, como nós já voltamos para o horizonte do mercado, a vida teatral passa a ser pautada pelos jornais. Pode ver que nessa data não é casual a coincidência da entrada triunfante do Gerald Thomas no 
teatro brasileiro e de todos os desdobramentos dos experimentos que ele fazia. E um dos maiores apoiadores do projeto Gerald Thomas como mercadoria teatral é a Folha de S.Paulo. Mas eu acho que o Grupo Opinião como pelo menos um endereço de resistência, em todos os sentidos, tem um valor igual ao Teatro São Pedro aqui em São Paulo. Porque eu estou falando de deserto de ideias, imagens, dramaturgia.

ASPAS - Uma das passagens mais conhecidas do Roberto Schwarz no “Cultura e política” é quando ele diz que, apesar da ditadura, você tinha uma relativa hegemonia cultural de esquerda. Como caracterizar essa hegemonia cultural de esquerda? 0 que isso significava?

INÁ - Vamos traduzir: o Brasil já estava plenamente inserido na indústria cultural. Ainda não tinha a TV Globo, porque ela foi criada propriamente em 1966 e virou realidade a partir de 1970 mais ou menos, mas a indústria cultural já existia, o rádio era poderosíssimo e já havia múltiplos canais de televisão divulgando o enlatado. Então, quando ele se refere à relativa hegemonia, ele já está fazendo um recorte sério em relação à cultura que dava dinheiro, que já era a indústria cultural dos anos 1960 e que explodiu! É só você pensar: a indústria de discos, o Roberto Carlos, a importação de artistas, importação no sentido de venda estrondosa de discos vagabundos! Isso tudo já tomava conta do cenário. E não é disto que ele está falando. O teatro fazia parte de um referencial cultural, por assim dizer, mais exigente e já era, quantitativamente, minoria visível, como também a literatura e o cinema. Pense nos grandes acontecimentos, como o filme Terra em transe, do Glauber Rocha, que foi visto por pouquíssima gente. É dentro do recorte "cultura mais exigente" que você tem uma relativa hegemonia da esquerda. Mas esta cultura mesmo, a exigente, não era nem hegemônica, era vítima de um massacre e já estava na mão da indústria cultural. Nós já tínhamos, por exemplo, a editora Abril vendendo lixo. Ela sempre produziu lixo, porque ela é uma filial de grupos editoriais americanos aqui no Brasil. As bancas de jornais e revistas já eram inundadas de lixo e os programas de televisão também! Não era monopólio ainda, mas você já tinha, praticamente, o monopólio da vida cultural assegurado pela televisão, rádio e indústria cultural. E essa era a cultura desprezada, com toda a razão, pelo povo da esquerda, mas ainda havia uma cultura 
exigente, coisa da qual nós não podemos falar mais hoje. Então, havia relativa hegemonia da cultura de esquerda dentro desse recorte severo que tem que ser feito no panorama geral.

ASPAS - No prefácio que você escreveu para o livro Brecht e a questão do método, do Fredric Jameson, tem uma passagem entre parênteses, em que você fala: "eu quase disse um processo de emburrecimento generalizado, mas me contive". Como você acha que se deu esse processo de emburrecimento generalizado da academia de 1968 para cá?

INÁ - Essa resposta está no Roberto Schwarz em "Cultura e política": a ditadura em 1964 liberou geral a paróquia, os valores religiosos que são hoje hegemônicos. O que nós tivemos foi o desenvolvimento lógico desse processo. E acho que, nesse capítulo, voltando para o panorama da cultura, não tem síntese melhor desse processo de destampatório que foi a ditadura em relação àquilo que estava sendo reprimido no início dos anos 1960 - a burrice, a grosseria - do que a Hebe Camargo. Ela é a melhor tradução da ignorância valorizada pela indústria cultural. Todo mundo queria ver o programa dela e os artistas queriam ser entrevistados por ela. Ela fazia as perguntas mais débeis mentais que alguém pode imaginar. $E$ eu estou falando da década de 1960! Mas isso era de se esperar, porque não houve um combate e nós fomos derrotados, a última derrota sendo em 1968 e não só aqui no Brasil, este ponto é fundamental. Nós fomos derrotados na França por um processo absolutamente escabroso, assim como nos Estados Unidos, onde, não se esqueçam, havia uma ponta de lança. A culminação da derrota norte-americana é nada menos que o assassinato do Martin Luther King em 1968. E, depois, você tem a perseguição igualmente hedionda aos Panteras Negras, a prisão da Angela Davis. A classe dominante, que é mundial, não estava para brincadeiras, mas aqui no Brasil parecia que estava. Aqui a coisa não chegou a um décimo da gravidade da França e dos Estados Unidos, para ficar em dois episódios, porque a Alemanha também entrou em movimento, a Itália. Em 1968 houve a última grande tentativa mundial de acabar com o capitalismo e ela foi derrotada. Ora, da mesma forma que aqui, em 1964, o combate ao comunismo foi um destampatório, em 1968, a vitória da classe dominante mundial foi um destampatório equivalente, só que com muito maior alcance, 
porque agora o alcance é mundial. Então a burrice, hoje, é a regra geral, virou um valor. É só você ver a desfaçatez grosseira dos apoiadores do Bolsonaro. E eu não me refiro a esses ignorantes que ganham dinheiro para carregar bandeira, eu me refiro a militantes que participam de chats e de todas essas discussões na internet, nas assim chamadas redes sociais. É a força bruta operando e a expressão mental da força bruta.

\section{ASPAS - E que as universidades ajudaram a produzir.}

INÁ - Nas universidades é diferente. Para essa análise, nós temos que começar pela França, em que a produção do discurso não é casual. $\mathrm{O}$ discurso pós-moderno começou na França no pós-1968. É só você ver quais são os vínculos e como, a partir da França, essa ideologia se difunde. $\mathrm{Na}$ verdade, essa ideologia desaguou no navio da Alemanha "pós-nazista", por isso Heidegger é a figura mais importante. Os pós-modernos restauram o pensamento do Heidegger em diferentes versões, mas são todos heideggerianos. Você pode pegar todos os heróis civilizadores franceses do fim dos anos 1960 e ao longo dos 1970. Eles são todos heideggerianos, sendo que tem duas figuras absolutamente eloquentes, uma se chama Michel Foucault e a outra se chama Jacques Derrida. E isto não é denúncia, eles se declaram como tais. E de lá tem a difusão, a universidade americana abraça esse pensamento e inunda os departamentos de humanas com essa baba chamada pós-moderna. No caso das artes, houve a retomada de uma pauta do século $\mathrm{XIX}$, que é o veto ao pensamento. Isso já vem do século XIX, da burguesia francesa após a Comuna de Paris. E, não por acaso, é depois da Comuna de Paris que o discurso da arte pela arte decola, embora ele já existisse antes. Mas por quê? Porque as pessoas começam a falar de coisa séria e olha no que dá! Tem o elemento preventivo, que é muito importante, e o reativo: toda vez que a burguesia toma um susto, ela reage em todos os níveis, sempre com a máxima brutalidade.

ASPAS - Em um dos seus textos, você afirma que, se houve alguma vez uma revolução no teatro brasileiro, essa se deu no CPC...

INÁ - Porque o CPC - hoje nós temos também o MST - foi a primeira formulação de uma proposta de produção teatral que rompia com o pensamento mercadológico. E isso é uma revolução, porque abandona a perspectiva de 
produzir segundo uma demanda, o que não é nem ideologia, é cretinice. O seu discurso estético passa a ser aquilo que o seu programa de intervenção política pede. A atuação é militante e você, ao atuar, tenta organizar o público ou politicamente, que é o caso do agitprop propriamente dito, ou pelo menos no plano da produção de uma arte que diz respeito a nós, à nossa vida e ao que nós fazemos. Passa a ser o "nóis e nóis" - aquele que o Moreira reclama -, quer dizer, vamos, entre nós, falar do que nos interessa, sabendo que nós vivemos em um mundo de opressão, de negação de direitos. Vamos falar dos direitos pelos quais nós lutamos, vamos falar das necessidades que nós temos. O CPC foi a única organização nesse sentido até o MST organizar as suas brigadas. Ele foi o único momento realmente revolucionário na arte brasileira. No século XIX e até a famosa greve de 1917 que teve aqui no Brasil, os anarquistas faziam isso! A diferença é que os anarquistas, como parte da ação política, já tinham produção teatral, músicas, festas e outras atividades. Já era luta revolucionária, então nem se colocava a questão. E por que eu posso falar que o CPC é o primeiro? Porque nós estamos falando de estudantes universitários pequeno burgueses e burgueses que descobrem que 0 que eles querem dizer não tem lugar na indústria cultural e nem no mercado teatral. Então é nesse sentido que é uma revolução.

\section{ASPAS - E você acha que esse continua sendo o nosso limite?}

INÁ - Até hoje. Porque eu, que participei intensamente de todo o processo do Arte Contra a Barbárie, vi que foram poucos os que se aproximaram do MST e que nenhum deles abriu mão da condição de grupo e de pequeno produtor, seja contando com o mercado, seja contando com - Estado. Eles produziam uma mercadoria e tinham com o mercado uma relação de pequeno produtor de mercadoria. Eu não me lembro de nenhuma exceção dentre os que eu conheço, ainda que possa haver, mas eu não tenho notícia. Nem o grupo mais radical, que é a Ensaio Aberto do Rio de Janeiro: ela continua sendo uma companhia de teatro.

ASPAS - Existe um pressuposto para todos nós de que a forma é sempre um conteúdo sedimentado. Só que hoje, pensando nesse império das curadorias, das mostras e todas as derivações possíveis, em que as 
próprias formas de atuação já foram em grande parte incorporadas, você acha que essa máxima continua valendo?

INÁ - Claro! Porque isso independe dessas mediações. A forma é sempre conteúdo sedimentado. Se você não cair no varejo, vai ver que qualquer obra é um conteúdo formado e a forma dessa obra é esse conteúdo sedimentado com todas as suas contradições. Aliás, esse é o grande conselho do Adorno: ao ouvir uma música, ao ler um romance, ao olhar para uma pintura ou fotografia ou ver um filme, atente para as contradições. Porque o mais eloquente, que é o conteúdo formado, vai aparecer na maneira como o artista, ou os artistas, no caso de um coletivo, lidaram com as contradições do seu conteúdo. Mas curadoria e essas coisas atuam no varejo e existe um termo médico para isso: ossificado. Ossificado é quando a cartilagem vai virando osso e "morre". Vou contar um caso que fiquei sabendo ontem e chega a ser genial, de tão óbvio. Uma pessoa do meu conhecimento escreveu um livro de contos e inscreveu o livro em um concurso literário em Portugal. Obviamente, se eu gostei, o livro nem se classificou. Mas na verdade a inscrição foi para fazer um teste (ao estilo brechtiano). Essa pessoa, por ter participado do concurso, recebeu o relatório da comissão e os elogios ao vitorioso. Um dos valores da comissão de um prêmio literário em Portugal, de acordo com os méritos do livro premiado, é a "perícia da construção dos enredos". Traduzindo: é aquela regrinha que já está no Aristóteles, depois no Forster e nos manuais de roteiro: começo, desenvolvimento, clímax, declínio e fecho... Estamos em 2018 e isso ainda é um valor para uma comissão que dá prêmio literário. Construção de enredo nada mais é que um conteúdo ossificado. Por este exemplo, você pode avaliar o processo como um todo. O que é isso? É a mixórdia, é a ignorância transformada em critério, é a irresponsabilidade e assim podemos continuar enumerando até enjoar.

\section{ASPAS - E como apontar as contradições em uma atmosfera tomada pelo cinismo e pelo louvor à ignorância?}

INÁ - Nesse tópico, é preciso lembrar que você está falando com uma pessoa que foi para trincheira de retaguarda. As providências práticas já não estão mais ao meu alcance. Se eu ainda estivesse no front, eu poderia dizer "olha, eu tenho feito isso, aquilo, aquele outro..., porque depende. Às vezes, é bom 
ver que aqueles critérios do Roberto com os quais nós começamos não são genéricos, isto é, não se aplicam abstratamente. Devem ser pensados em cada situação (para lembrar também do Debord). Porque, de repente, como ensina um dos personagens do Brecht, o sr. Keuner, diante de uma inundação, o que você tem a fazer é afundar e deixar a onda passar para depois boiar. É assim que se faz na praia. Vou explicar por que eu era nadadora: se você está em um lugar que ainda dá pé e, de repente, se forma uma onda muito maior que você, a providência é afundar. Não resista! Você enche o pulmão de ar e afunda; depois que a onda passa, você volta. Você nem ao menos se machuca. Eu dei a sorte de ter apreendido a nadar muito criança. E assim como você precisa aprender a lidar com as forças da natureza de modo a continuar inteiro, não cair, não se arrebentar, não se quebrar, não se afogar, não se queimar, tem várias coisas que você vai aprendendo. Ora, na vida acadêmica é a mesma coisa. Se nós estamos passando por um período de inundação de lixo, a melhor coisa a fazer é mergulhar e deixar passar; depois voltar à tona e ver o que dá para fazer. Acho que está errado o que muita gente que eu conheço está pensando e já fez, que é cair fora. Nós não podemos entrar nessa linha de avaliar o outro do ponto de vista moral, porque não é um problema moral, é político! Não tenho a menor dúvida de que, no caso de vocês, isso se dá de maneira mais acentuada, mas os nossos companheiros não têm culpa de terem a cabeça que têm. Foi o que a instituição Ihes ofereceu. Então tem que descobrir um jeito de conviver com isso. Alguns são irrecuperáveis, mas muita gente pode ser resgatada. Eu tenho consciência de ter resgatado pelo menos uma meia dúzia. Operação resgate mesmo. Quando perceber que o interlocutor está papagueando, pegar leve, chamar para conversar sobre outra coisa... Esta é a operação resgate no varejo. No atacado, a sala de aula pode ser um exemplo. Eu não tenho dúvida de que, na minha experiência como professora, muitos escaparam - eu estou falando das Letras - da lama pós-moderna porque foram meus alunos. No primeiro dia de aula, eu entrava em sala e já avisava: "Vejam bem: eu tenho duas referências que são essenciais, uma é o Anatol Rosenfeld e a outra é o Antonio Candido. Quem não quiser ser doutrinado em direção ao pensamento do Anatol Rosenfeld e do Antonio Candido, vá procurar outro professor. Têm mais sete professores dando a mesma disciplina, vocês podem procurar qualquer outro." Esse é o 
outro ponto: jogar limpo. O inimigo joga sujo da maneira mais nojenta possível. Aliás, um dos meus gurus é o Chomsky. Isso é bem mais recente, embora eu já soubesse dele quando eu fiz Letras, mas nessa época eu só conhecia o Chomsky da Linguística. E já gostava dele, porque ele tem uma teoria materialista do desenvolvimento, da apropriação do código lingüístico, mas eu não tinha nenhum livro dele. Estou falando de 1970! E bem depois eu realmente descobri o grande Chomsky, porque ele é um arquipélago. Ele é um dos melhores críticos da política imperialista norte-americana, para não ir mais longe. Pois bem, o Chomsky falando do pós-moderno é uma maravilha, porque ele diz que o pós-moderno tem três anti-valores: 1) não existe verdade; 2) não existe realidade; e 3) tudo é discurso e inconsequência. E eles praticam isso de maneira sistemática. Então o que fazer? É melhor conversar sobre outras coisas, porque com uma pessoa que não acredita em verdade nem em realidade, você vai conversar o quê?

\section{ASPAS - Sobre experiência... Essa é a palavra de ordem dos estudos de teatro contemporâneo: a experiência, o encontro, a relação...}

INÁ - E não importa no que dê, porque não é real, é subjetivo. E as subjetividades se multiplicam, porque não existe intercâmbio. Agora, experiência? Vamos falar sobre experiência! Tem um ensaio do Walter Benjamin sobre isso, que já desmente inclusive o conceito científico de experiência. Mas o problema dos pós-modernos é que eles não levam nada muito a sério e para valer. Eu já vi, por exemplo, leituras de textos dialéticos que os transformam em outra coisa, inclusive em seu contrário. Brecht é uma das maiores vítimas que eu conheço. Mas, de novo: o patamar em que estamos é o da burrice universalizada. E a tristeza é que ela não é uma exclusividade do Brasil. Como diz uma peça que vocês devem conhecer, Apareceu a Margarida, de Roberto Athayde... A dona Margarida era uma professora enlouquecida, a encarnação da ditadura, que esculhambava os alunos dizendo: "Porque no Brasil isso! Porque no Brasil aquilo! E nos Estados Unidos é a mesma coisa." Pois bem, dando uma de dona Margarida, meu consolo é que nos Estados Unidos é muito pior! Lá você tem a violência organizada, inclusive na academia. Aliás, ontem eu fiquei sabendo que uma das organizações que está renascendo com tudo é a Ku Klux Klan. Mas, dialeticamente, a boa notícia é que isso é sintoma 
de que o capitalismo está nas últimas! Um fato, nos Estados Unidos, desde a década de 1920 é que eles são uma pseudodemocracia. Isso é demonstrado por Chomsky em inúmeros livros. O maior dos mitos em que o norte-americano acredita é que aquilo é uma democracia. E, desde a eleição do Trump, ficou claro que a burguesia norte-americana não está mais comprometida nem com o mito da democracia. Mas por quê? Porque caiu a ficha de que não tem para onde correr, não tem para onde ir. 0 colapso do capitalismo, que começou em 2008, se aprofunda. Essa é a boa notícia! Talvez nós sejamos partícipes do processo de destruição final, seguido ou concomitante de uma reconstrução do mundo, porque agora ou o processo é mundial ou não é. Não tem mais a chance de dar certo uma revolução como em Cuba e ficar só lá: o processo será mundial ou não será. Aliás, em uma das intervenções desse filme que eu falei sobre 1968 já está esta palavra de ordem: a revolução tem que ser mundial! E parece que tem bastante gente se organizando para isso. Essa é a boa notícia! Eu achei, não faz muito tempo, o site do SWP-UK, o Socialist Workers Party do Reino Unido, e eles dão como certa a queda da Theresa May por esses dias. Dois ministros acabaram de se demitir, e o gabinete dela está se esfarelando. É verdade que o Brexit é parte disso, mas não é só. E pode ser possível que ela, Theresa, tenha que convocar nova eleição. É seguro que, nesse caso, ganhe o Jeremy Corbyn, apoiado pelo SWP, com um programa praticamente revolucionário. Que tal? Tem muita notícia boa pelo mundo afora! É uma das vantagens de estar na retaguarda. Agora eu tenho tempo para tomar conhecimento de tudo isso. Lembrei de mais uma que foi genial, mas não vou lembrar quem foi que comentou. Nessa guerra de tarifas que o Trump declarou à China, alguém fez o seguinte comentário: "Isso é cachorro latindo para elefante! Um cachorro poodle! Se o elefante quiser, é só pisar!" É isso que está acontecendo. E isso, para mim, é tudo notícia boa. Mas voltando ao nosso tema, para pensar nos 1950 anos desde 1968, é muito importante buscar as referências mundiais e entender que, por mais diferente que seja o que aconteceu nos Estados Unidos, é tão relevante quanto o que aconteceu na França. O Breno Altman fala que o Charles de Gaulle já tinha renunciado e aí seria revolução, cairia o governo e os mobilizados iriam tomar o poder, seria a segunda Comuna de Paris. Mas os comunistas ficaram com medo e, entre comunistas, lembre-se que tinha Moscou, que dava ordens ao 
Partido Comunista Francês. O Breno não fala isso, mas eu sei. Foi Moscou que telefonou para o Partido Comunista Francês, e mandou recuar, porque Moscou, em plena Guerra Fria, ainda achava que, se os franceses avançassem, ia sobrar para a URSS a guerra nuclear, toda essa bobajada que serviu para pôr panos quentes. Agora Moscou não manda mais e a China faz o negocinho dela sem fazer alarde... Em 1968, nos Estados Unidos, você tem a luta dos jovens pelo fim da intervenção norte-americana no Vietnã, uma luta de consequências políticas astronômicas e por isso tão violentamente reprimida. E essa era uma luta que corria paralela à dos negros pelos direitos civis. O edifício da pseudodemocracia americana estava mesmo ameaçado. Aliás, teve alguém que batizou o regime americano, não vou me lembrar quem, de conglocleptocracia, que é a cleptocracia dos conglomerados. E já era uma cleptocracia depois do fim da Primeira Guerra Mundial, que agora está caindo. Motivo para ser otimista é o que não falta, é só olhar para onde as coisas estão acontecendo de verdade.

Edição de Roberta Carbone

Publicado em 06/05/2019 